\title{
Modeling of battery pack sizing for electric vehicles
}

\author{
V. Sandeep ${ }^{1}$, Suchitra Shastri' ${ }^{2}$, Arghya Sardar ${ }^{3}$, Surender Reddy Salkuti $^{4}$ \\ ${ }^{1}$ Department of Electrical Engineering, National Institute of Technology Andhra Pradesh, India \\ ${ }^{2}$ Department of Electrical Engineering, Central University of Karnataka, Kalaburagi, India \\ ${ }^{3}$ Technology Information Forecasting and Assessment Council, New Delhi, India \\ ${ }^{4}$ Department of Railroad and Electrical Engineering, Woosong University, Daejeon, Republic of Korea
}

\begin{tabular}{l} 
Article Info \\
\hline Article history: \\
Received Nov 23, 2019 \\
Revised Apr 26, 2020 \\
Accepted May 19, 2020 \\
\hline
\end{tabular}

\section{Keywords:}

Battery pack sizing

Braking losses

Electric vehicles

Storage battery

Kinetic energy

Optimization

\section{Corresponding Author:}

Surender Reddy Salkuti,

Department of Railroad and Electrical Engineering,

Woosong University,

17-2, Jayang-Dong, Dong-Gu, Daejeon 34606, Republic of Korea.

Email: surender@wsu.ac.kr

\begin{abstract}
The paper presents the mathematical modeling for battery pack sizing to evaluate the vehicle energy consumption by using the derivation from Parametric Analytical Model of Vehicle Energy Consumption (PAMVEC) by Simpson in R Studio. The assess of storage batteries for electric vehicles (EVs) application is presented in this paper. The main source of power in EVs are batteries and to properly optimize their use in them, a parametric vehicle dynamic model is created and factors like battery mass, energy needed for the EV etc. are predicted using inputs such as battery specific energy, range etc. An assessment of output parameters is performed by using different batteries and compared to determine best battery for EV application.
\end{abstract}

This is an open access article under the $\underline{C C B Y-S A}$ license.

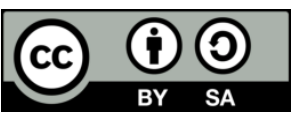

\section{NOMENCLATURE}

$\begin{array}{ll}\mathrm{a} & \text { Acceleration } \\ \mathrm{g} & \text { Acceleration due to gravity } \\ \mathrm{m} & \text { Mass of vehicle } \\ A_{f} & \text { Frontal area }\left(\mathrm{m}^{2}\right) \\ C_{\text {cell }} & \text { Cell capacity } \\ C_{\text {rate }} & \text { Discharge rate of cell } \\ V_{c} & \text { Cell voltage } \\ \mathrm{f} & \text { Ratio between total cell weight to battery weight } \\ V_{\text {grade }} & \text { Gradient of vehicle with respect to road } \\ \mathrm{v} & \text { Voltage } \\ P_{\text {road }} & \text { Road load power }(\mathrm{W}) \\ v & \text { Vehicle speed }(\mathrm{m} / \mathrm{s})\end{array}$

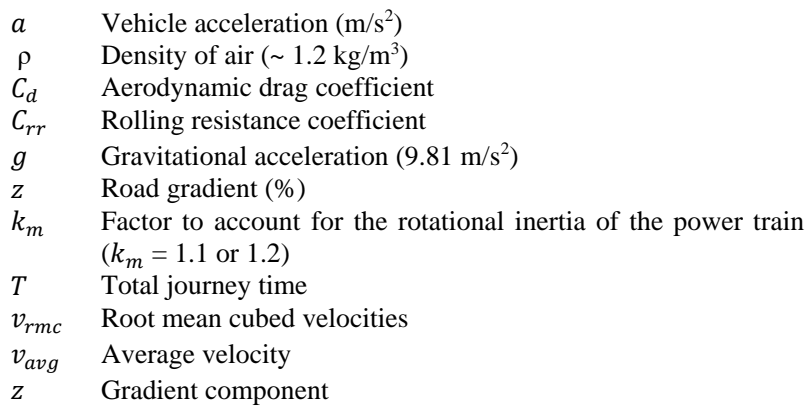

\section{INTRODUCTION}

Renewable energy resources (RERs) plays a very significant role in planning and operation due to no emissions and clean electricity production. During the last few years, a wide installation of RERs has been promoted to the power system. The energy production from these RERs is the leading solution towards the decarbonization of the society and the security of energy supply. However, various issues of intermittency of 
RERs and the constraints for the connection of electric vehicles (EVs) should be effectively addressed [1]. Energy storage could be one option to handle the uncertainty of RERs. More efficient operation of market is required to accommodate flexible demand and electric vehicle (EV) charging and discharging. EV is a type of vehicle that uses electricity to run. There are three main components in EVs, i.e., electric motor, battery pack and a non-conventional transmission that transfers the motor power to the wheels. While driving, the battery power is used and depleting its supply. The batteries in EVs need to be charged regularly. The battery EVs offer about (100-150) km driving range before needing to be recharged [2]. But actual driving range depends on the driving style, speed driven, climate control usage and weather. EVs use low drag aerodynamic shapes, use highly advanced technology, reduced weight and fuel costs and zero emissions [3].

EVs are considered as an important technology to reduce fossil fuel consumption, emissions and energy consumption. But, the EVs require larger battery packs to reach acceptable range levels. The development of new batteries with higher specific energy could reduce the mass and the cost of EVs and increase their driving range [4]. The design and optimization of the battery pack in an EV is essential for the integration of EVs into global market [5]. EVs can also be used to smooth out the varying fluctuations in the energy profile of output energy generated by the sources. Energy storage from electric vehicles' batteries can act as a network of mobile storage systems, which can also help to support the grid by providing real backup power and improving the energy profile by providing reactive power compensation. Therefore, batteries are considered one of the widely used energy storage systems [6]. EVs are cheaper to run compared to conventional petrol/diesel vehicles, they are eco-friendly, cheaper to maintain, and can be charged from RERs such as solar, wind and geothermal, etc.

The batteries used for EVs are lead-acid, nickel-based, and lithium-ion. Lead-acid batteries were used in EVs in early generation [7]. The present trend for electric mobility is towards using lithium-ion battery. As lead-acid batteries are of low cost but they have low specific energy and have more weight. Nickel-metal hydride batteries were also prominence for the use of EVs, but lithium-ion batteries are more prominence towards the use of electric and hybrid EVs [8].

A battery-powered EV model along with a simple simulation-based iterative method of battery sizing is proposed in [9]. Reference [10] proposes a new battery cooling system for hydrogen fueled hybrid EVs that achieves more efficient cooling and driving, which increases vehicle driving range and enhances vehicle safety by maintaining the batteries at optimum operating conditions. A customer adaption cost that decreases with battery energy capacity is proposed in reference [11]. Reference [12] provides a basic guideline for cell selection and integration of cell for the EVs battery pack. An effective battery thermal management system solution is presented in reference [13]. Various EV battery technologies are presented in [14]. Modeling and simulation of battery EVs has shown in reference [15] that the choice of battery technology has a high impact on vehicle performance. Reference [16] proposes a mathematic model for the simulation of battery packs based on element wise calculations of matrices. The study and modeling of a lithium-ion battery cell is presented in reference [17].

For construction of future scenarios, trends in energy storage technologies were discussed in this paper. A simulation model which takes vehicle parameters and cell parameters (specific energy, voltage, discharge rate etc.) as inputs and provides estimates the energy storage requirement for the vehicle is developed [18]. It is observed that for likely future scenarios of battery technology, there could be significant positive impact on the cost and/ or performance of EVs. In this work, it is assumed that there is no change in the vehicle design or component sizing. The vehicle is assumed to remain same as in its present form, except the fact that the battery pack is constructed with cells of emerging technologies. Therefore, it is possible to have higher benefits as compared to the results shown in the present work. The application of these batteries for EVs is presented in this paper. The main source of power in EVs are batteries and to properly optimize their use in them, a parametric vehicle dynamic model is created and factors such as battery mass, energy needed for an EV are predicted by using inputs like battery specific energy, range etc [19]. An assessment of output parameters is performed by using different batteries, and compared to determine best battery for EV application.

The remainder of this paper is organized as follows: Section 2 presents the detailed mathematical modeling of battery pack sizing. Simulation results and discussion is presented in Section 3. Finally, the contributions with concluding remarks are presented in Section 4.

\section{MATHEMATICAL MODELING OF BATTERY PACK SIZING}

The prediction of range and performance of electric vehicles (EVs) is important. Three important parameters in this regard are range per charge of battery, maximum speed and acceleration. Development of a mathematical model to estimate these performance parameters for various hypothetical future batteries will require consideration of fundamental equations of the vehicle dynamics. The performance of a given vehicle 
depends to a large extent on the driving cycle it follows. A driving cycle is time vs speed profile of the vehicle. Since there are infinite number of possibilities for such driving pattern in real life, typically a standard time vs speed profile is defined based on statistical analyses and such a standard driving cycle is accepted for various regulatory purposes [20]. Modified Indian Driving Cycle (MIDC) is the driving cycle accepted in India. The fuel economy of vehicles are tested with respect to this driving cycle. Vehicle manufacturers in India report mileage/fuel economy with respect to this MIDC driving cycle. Similarly, standard driving cycles are available in other countries such as United States of America, Europe, and Japan etc. By using standard mathematical equations and spreadsheets, the simulation can be done in MATLAB and Excel sheets. Inputs to model are various vehicle attributes such as mass of the vehicle, its dimensions, gear ratio, wheel base speed, motor power etc., and it is necessary to have a good performance of the vehicle so that it can achieve the target of a current IC engine vehicle. Another important aspect for EVs is its range [21-22]. A mathematical model is developed to calculate the range of vehicle based on the type of battery and its capacity. Figure 1 depicts the road load equations of EV.

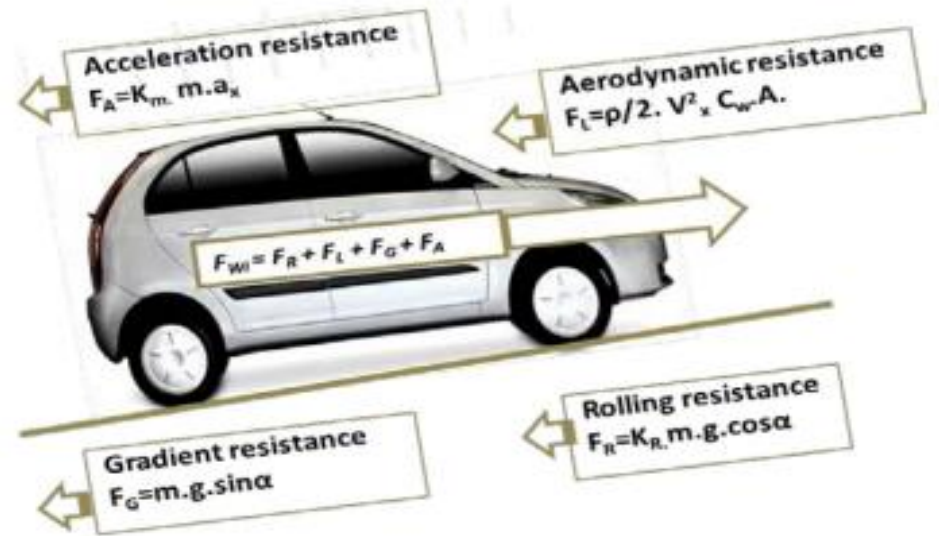

Figure 1. Flow chart of cuckoo search algorithm.

\subsection{Power consumption by a vehicle}

While running, a vehicle needs to overcome four forces opposing, they are motion - aerodynamic drag, rolling resistance, a component of its weight depending on the gradient, and its inertia. Since the power consumption is obtained by multiplying the force with velocity, and since the velocity of the vehicle changes continuously during its movement. Typically, simulators are used to estimate power consumption at each simulation steps. The energy consumption is obtained by integrating the power consumption values over time [23].

However, a parametric approach for estimating vehicle energy consumption has been introduced by Simpson et al. in reference [24]. The model developed by them is known as Parametric Analytical Vehicle Energy Consumption (PAMVEC). The fundamental concept of this approach is to de-couple the total tractive forces into two separate categories. First one comprises the aerodynamic drag and rolling resistance, which are non-recoverable. The other one comprises the gradient related force and inertia, which result in change in potential or kinetic energy of the vehicle, and can be recovered. Simpson et al. have shown that a driving cycle can be represented by four parameters: average speed, root mean cubed velocity, velocity ratio, and characteristic acceleration [25].

\subsection{Average road load power}

The modeling of vehicle energy consumption is approached by the parametric description of following road load equations [26],

$$
\begin{aligned}
& P_{\text {road }}=P_{\text {aero }}+P_{\text {roll }}+P_{\text {accel }}+P_{\text {grad }} \\
& P_{\text {road }}=\frac{1}{2} \rho C_{d} A v^{3}+C_{r r} m_{\text {total }} g v+k_{m} m_{\text {total }} a v+m_{\text {total }} g z v
\end{aligned}
$$

Equation (1) is the average road load power equation, and it consists of four components. $P_{\text {aero }}$ and $P_{\text {roll }}$ are irreversible power losses due to aerodynamic and rolling drag, whereas $P_{\text {accel }}$ and $P_{\text {grad }}$ are the 
power for vehicle acceleration and hill-climbing, representing the potential and kinetic energy, and they are recoverable [27]. This assumption makes $P_{a c c e l}$ and $P_{\text {grad }}$ equal to zero, i.e.,

$$
\int_{0}^{T} P_{\text {accel }}=0 \text { and } \int_{0}^{T} P_{\text {grad }}=0
$$

In order to parameterize the road load equation, it is assumed that a vehicle's journey is defined as including the return trip to its point of departure [28]. Similarly,

$$
\int_{0}^{T} K_{m} m_{\text {total }} a v d t=0 \text { and } \int_{0}^{T} m_{\text {total }} g z v d t=0
$$

These are valid as the net change in speed and elevation is zero. Since, the vehicle returns over the journey to its point of departure, the elevation and net change in speed is zero.

$$
P_{\text {road }}=\frac{1}{2} \rho C_{d} A v_{r m c}^{3}+C_{r r} m_{\text {total }} g v_{\text {avg }}
$$

where $v_{\text {avg }}=\frac{1}{T} \int_{0}^{T} v d t$ and $v_{r m c}=\sqrt[3]{\frac{1}{T} \int_{0}^{T} v^{3} d t}$. The driving pattern velocity ratio $(\Lambda)$ is defined as the ratio of $v_{r m c}$ to $v_{a v g}$. From this, the average road load power is expressed as [29],

$$
P_{\text {road }}=\frac{1}{2} \rho C_{d} A \Lambda^{3} v_{r m c}^{3}+C_{r r} m_{\text {total }} g v_{\text {avg }}
$$

Equations (5) and (6) accounts for gravitational energy and inertial losses as a part of vehicle road load. These two losses are due to inefficient mechanisms in vehicle power train.

\subsection{Average braking losses}

The friction brakes dissipates the gravitational energy and kinetic energy stored within the inertia of the vehicle [30]. The average rate of energy stored is determined within the inertia of a vehicle. Therefore, to derive the average rate of energy storage, the following equation is considered.

$$
P_{\text {recoverable }}=m_{\text {total }}\left(k_{m} a+g z\right) v
$$

Let $a_{e}=k_{m} a+g z$. The gradient component and acceleration both can be represented by single acceleration term. The average rate of energy storage in vehicle inertia $\left(P_{\text {inertia }}\right)$ is written by assuming the gradient of zero, i.e.,

$$
P_{\text {inertia }}=\left.\frac{1}{T} \int_{0}^{T} k_{m} m_{\text {total }} a v\right|_{a \geq 0}
$$

Here, to substitute a parametric equation, positive acceleration kinetic energy per unit distance (PKE) is introduced, which is a measure of acceleration work required in a driving pattern. PKE is the sum of distances between the squares of the final and initial velocities in successive acceleration, dividing by total trip distance. It is expressed by using [31],

$$
P K E=\frac{\sum\left(v_{\text {final }}^{2}-v_{\text {initial }}^{2}\right)}{D}=\frac{\sum\left(v_{\text {final }}^{2}-v_{\text {initial }}^{2}\right)}{\int_{0}^{T} v d t}
$$

The average rate of kinetic energy (KE) storage [32] in a vehicle during driving cycle is represented by,

$$
P K E \times v_{\text {avg }}=\frac{\sum\left(v_{\text {final }}^{2}-v_{\text {initial }}^{2}\right)}{T}
$$

The average rate of KE storage in a vehicle mass during a driving pattern is expressed as,

$P_{\text {inertia }}=\frac{\sum\left(\frac{1}{2} k_{m} m_{\text {total }} v_{\text {final }}^{2}-\frac{1}{2} k_{m} m_{\text {total }} v_{\text {initial }}^{2}\right)}{T}$

The equation for energy storage within vehicle inertia is given by, 


$$
P_{\text {inertia }}=\frac{1}{2} k_{m} m_{\text {total }} v_{\text {avg }} P K E
$$

The above equation is a parametric expression for the average rate of energy storage, which is a consistent form of $P_{a c c e l}$ in equation (1). Therefore, the characteristic acceleration ( $\left.\tilde{a}\right)$ can be expressed as,

$$
\tilde{\mathrm{a}}=\frac{1}{2} \mathrm{PKE}=\frac{1}{2} \frac{\sum\left(v_{\text {final }}^{2}-v_{\text {initial }}^{2}\right)}{\mathrm{v}_{\mathrm{avg} \mathrm{T}}}
$$

The average rate of energy storage in the vehicle inertia over a driving cycle, assuming a flat road is given by,

$$
P_{\text {inertia }}=k_{m} m_{\text {total }} v_{\text {avg }}(\tilde{a})
$$

The average braking losses can be defined by using the regenerative braking fraction $\left(k_{r e g e n}\right)$, and it can be expressed as,

$$
P_{\text {braking }}=\left(1-k_{\text {regen }}\right)
$$

Then, the $P_{\text {inertia }}$ can be expressed as,

$$
P_{\text {inertia }}=\left(1-k_{\text {regen }}\right) k_{m} m_{\text {total }}(\tilde{\mathrm{a}}) v_{\text {avg }}
$$

The equations (6) and (16) can be combined to get the average power requirement at the output on the driven axle of a vehicle, i.e., power at drive shaft is equal to power due to road load and power due to braking [33], and it can be expressed as,

$$
P_{\text {drive-out }}=\frac{1}{2} \rho C_{d} A v^{3} v_{\text {avg }}^{3}+C_{r r} m_{\text {total }} g v+\left(1-k_{\text {regen }}\right) k_{m} m_{\text {total }}(\tilde{\mathrm{a}}) v_{\text {avg }}
$$

As $k_{\text {regen }}$ tends to 1 , braking losses tend to become zero, the potential and kinetic energy is returned for recapture of the power train. If there would be $100 \%$ efficiency of storage mechanism and energy recapture, no energy consumption would affect due to gravitation and inertia.

\section{RESULTS AND DISCUSSION}

In this paper, a spreadsheet model is developed to calculate the parameters of the Modified Indian Driving Cycle (MIDC), namely, average velocity, root mean cubed velocity, velocity ratio and characteristic acceleration. To model the impact of battery technology, it is important to predict the performance of a vehicle based in terms of criteria's, such as: top speed, i.e., maximum speed of the vehicle $(\mathrm{km} / \mathrm{h})$, driving range, and acceleration time, i.e., time taken for the vehicle to reach from minimum speed to maximum speed(s) (Table 1). The model considers input vehicle specifications and some details about the energy storage technology used are specific energy, specific power, cell voltage etc. The main outputs obtained are the maximum speed, range and acceleration time. After extracting the vehicle parameters form the specifications table, then the tyre outer diameter and motor base speed can be calculated.

The Indian driving cycle, i.e., speed vs time graph is depicted in Figure 2. The parameters of Indian driving cycle taken from spreadsheet calculation are as follows: total time is 196s, total distance < $1022.67 \mathrm{~km}, v_{\text {avg }}<-5.22, v_{r m c}<-3.26, A_{c h}<-0.27$ and velocity ratio $<-0.62$. Various constants considered in this paper are $\rho$ is $1.225, \mathrm{~g}$ is $9.81, C_{d}$ is $0.3, C_{r r}$ is $0.01, \mathrm{k}$ is $1.1, k_{r}$ is 0.3 . Once the vehicle attributes are obtained, the motor and transmission efficiencies are assumed, and other such constants. The necessary values of $v_{r m c}$ and $v_{a v g}$ are calculated from the velocities obtained from the drive cycles. And other parameters such as initial cell mass and maximum acceleration are also calculated.

The vehicle dynamics equations are now evaluated and the battery mass is optimized. The equations for mathematical model is taken from Parametric Analytical Model of Vehicle Energy Consumption (PAMVEC) by Simpson. It explains the energy consumption model which predicts the total energy consumed by the vehicle, by parametric driving cycle and vehicle attributes as an input. The derivation outlines the parametric formulation of road load equation. 
The obtained results by using the proposed approach are: battery power is $17920 \mathrm{~W}$, battery energy is $12185.6 \mathrm{Wh}$, maximum speed is $101.09 \mathrm{~m} / \mathrm{s}$, motor base speed is $9554.14 \mathrm{rpm}$, acceleration time is $20.63 \mathrm{~s}$ and energy consumption per $\mathrm{km}$ is $160.87 \mathrm{Wh}$.

Table 1. Technical vehicle specification of Mahindra's e2O Plus electric vehicle.

\begin{tabular}{cccc}
\hline Parameter & Value & Parameter & Value \\
\hline Top speed & $85 \mathrm{~km} / \mathrm{h}$ & Grade speed & $10 \mathrm{kmph}$ \\
Target range & $140 \mathrm{~km}$ & Overall gear & 10.83 \\
Acceleration minimum speed & $0 \mathrm{kmph}$ & Wheel diameter & $14 \mathrm{inch}$ \\
Acceleration maximum speed & $60 \mathrm{kmph}$ & Side wall height & $99 \mathrm{~mm}$ \\
Acceleration time & $9.5 \mathrm{~s}$ & Motor power & $19 \mathrm{~kW}$ \\
Glider mass & $1257 \mathrm{~kg}$ & Motor torque & $70 \mathrm{Nm}$ \\
Passenger weight & $320 \mathrm{~kg}$ & Consumption & $88 \mathrm{Wh} / \mathrm{km}$ \\
Cell specific energy & $170 \mathrm{Wh} / \mathrm{kg}$ & Battery capacity & $280 \mathrm{Ah}$ \\
Gradient PC & $18 \%$ & Number of modules & 16 \\
Frontal area & $2.496 \mathrm{~m}$ & Number of cells & 64 \\
Pack voltage & $72 \mathrm{~V}$ & Battery kWh & $15 \mathrm{kWh}$ \\
Cell capacity & $70 \mathrm{Ah}$ & Battery weight & $112 \mathrm{~kg}$ \\
Discharge rate & $0.5 \mathrm{C}$ & Cell specific power & $200 \mathrm{~W} / \mathrm{kg}$ \\
Cell voltage & $3.2 \mathrm{v}$ & Grade speed & $10 \mathrm{kmph}$ \\
Cell to battery weight & 0.8 & Overall gear & 10.83 \\
\hline
\end{tabular}

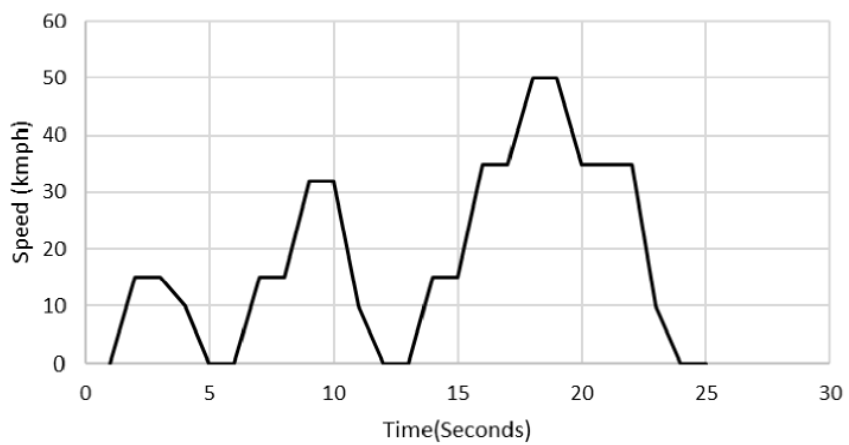

Figure 2. Indian driving cycle.

\subsection{Impacts of future developments in energy storage technologies on EVs}

Range/mileage: The mileage of vehicle can be improved if the specific energy of the battery increases. This results in longer driving range for the same battery mass. Hence, one will need lesser stops for charging, also leading to lesser impact on the grid. The goal is to achieve the range in an EV equal to what is seen in a petroleum based vehicles for the same amount of fuel (to achieve specific power close to that of gasoline/diesel in batteries).

Battery mass reduction for same power: If the power is kept same and the specific energy increased, then the mass can be reduced due to increase in energy output per kg weight. This in-turn effects the load of the vehicle and decreases the energy consumed per $\mathrm{km}$, adding to the increase in range.

Lifecycle improvement: Development in batteries could also potentially affect the increase in lifecycles of the battery, leading to longer battery lifetimes, and hence increasing the life of the battery.

Faster charging: Development in batteries could potentially lead to faster charging (with same charging power) from the electrochemical change in the batteries.

\section{CONCLUSIONS}

This paper has analyzed the possible future improvements in energy storage technologies that have various applications such as electric vehicles (EVs). Modeling of battery pack sizing for EVs has been presented in this work. The objective of this paper is to conduct and analyze the impacts of futuristic/emerging battery technologies. It is not possible to consider detailed battery characteristics such as its charge-discharge characteristics etc., as such data are not available for the emerging battery chemistry. Such issues are typically considered at the time of actual design of the vehicle battery pack. However, this work does not require a detailed design of vehicle battery pack. The future work can be focused on flow 
batteries and their use in EVs and their impacts on EVs. As the flow batteries are also more efficient than the rechargeable batteries, but the disadvantage is of its structure. Therefore, more concentration on reducing the structure and weight of the flow batteries can be done.

\section{ACKNOWLEDGEMENTS}

This research work has been carried out based on the support of "Central University of Karnataka's Academic Research Funding - (2019-2020)" and "Woosong University's Academic Research Funding (2019-2020)".

\section{REFERENCES}

[1] S.C.A. de Almeida, F.L.A. Vieira, "Modeling and Analysis of an Electric Vehicle using PAMVEC", Engenharia Térmic a (Thermal Engineering), vol. 17, no. 2, pp. 37-40, Dec. 2018.

[2] M. Mathew, Q.H. Kong, J. McGrory, M. Fowler, "Simulation of lithium ion battery replacement in a battery pack for application in electric vehicles", Journal of Power Sources, vol. 349, pp. 94-104, May 2017.

[3] E. Chemali, M. Preindl, P. Malysz, A. Emadi, "Electrochemical and Electrostatic Energy Storage and Management Systems for Electric Drive Vehicles: State-of-the-Art Review and Future Trends," IEEE Journal of Emerging and Selected Topics in Power Electronics, vol. 4, no. 3, pp. 1117-1134, Sept. 2016.

[4] I.B. Weinstock, "Recent advances in the US Department of Energy's energy storage technology research and development programs for hybrid electric and electric vehicles," Journal of Power Sources, vol. 110, no. 2, pp. 471-474, Aug. 2002.

[5] P.T. Moseley, B. Bonnet, A. Cooper, M.J. Kellaway, "Lead-acid battery chemistry adapted for hybrid electric vehicle duty," Journal of Power Sources, vol. 174, no. 1, pp. 49-53, Nov. 2007.

[6] G. Mulder, N. Omar, S. Pauwels, M. Meeus, F. Leemans, B. Verbrugge, W.D. Nijs, P.V. Bossche, D. Six, J.V. Mierlo, "Comparison of commercial battery cells in relation to material properties," Electrochimica Acta, vol. 87, pp. 473-488, Jan. 2013.

[7] T.K. Ying, X.P. Gao, W.K. Hu, F. Wu, D. "Noréus, Studies on rechargeable NiMH batteries," International Journal of Hydrogen Energy, vol. 31, no. 4, pp. 525-530, Mar. 2006.

[8] A.M. Jarushi, N. Schofield, "Battery and supercapacitor combination for a series hybrid electric vehicle," 5th IET International Conference on Power Electronics, Machines and Drives, Brighton, UK, 2010, pp. 1-6.

[9] M.G. Carignano, J.M. Cabello, S. Junco, "Sizing and performance analysis of battery pack in electric vehicles," IEEE Biennial Congress of Argentina (ARGENCON), Bariloche, 2014, pp. 240-244.

[10] M. Al-Zareer, I. Dincer, M.A. Rosen, "Performance assessment of a new hydrogen cooled prismatic battery pack arrangement for hydrogen hybrid electric vehicles," Energy Conversion and Management, vol. 173, pp. 303-319, Oct. 2018.

[11] M.W. Verbrugge, C.W. Wampler, "On the optimal sizing of batteries for electric vehicles and the influence of fast charge," Journal of Power Sources, vol. 384, pp. 312-317, Apr. 2018.

[12] L.H. Saw, Y. Ye, A.A.O. Tay, "Integration issues of lithium-ion battery into electric vehicles battery pack," Journal of Cleaner Production, vol. 113, pp. 1032-1045, Feb. 2016.

[13] J. Kim, J. Oh, H. Lee, "Review on battery thermal management system for electric vehicles", Applied Thermal Engineering, vol. 149, pp. 192-212, Feb. 2019.

[14] R. Garcia-Valle, J.A. Pec sas Lopes (eds.), "Electric Vehicle Integration into Modern Power Networks, Power Electronics and Power Systems," Springer Science Business Media New York, 2013.

[15] D. Hülsebusch, S. Schwunk, S. Caron, B. Propfe, "Modeling and simulation of electric vehicles - The effect of different Li-ion battery technologies," The 25th World Battery, Hybrid and Fuel Cell Electric Vehicle Symposium \& Exhibition, EVS-25 Shenzhen, China, Nov. 5-9, 2010.

[16] F. Chang, F. Roemer, M. Baumann, M. Lienkamp, "Modelling and Evaluation of Battery Packs with Different Numbers of Paralleled Cells," World Electric Vehicle Journal, vol. 9, no. 8, pp. 1-15, 2018.

[17] E. Vergori, F. Mocera and A. Somà, "Battery modeling and simulation using a programmable testing equipment," 2017 9th Computer Science and Electronic Engineering (CEEC), Colchester, pp. 162-167, 2017

[18] J. Seo, S. Sankarasubramanian, C.S. Kim, P. Hovington, J. Prakash, K. Zaghib, "Thermal characterization of $\mathrm{Li} /$ sulfur, Li/ S-LiFePO4 and Li/S-LiV3O8 cells using Isothermal Micro-Calorimetry and Accelerating Rate Calorimetry," Journal of Power Sources, Vol. 289, pp. 1-7, 2015.

[19] J. Larminie, J. Lowry, "Electric Vehicle Technology Explained", John Wiley \& Sons Ltd, England, 2003.

[20] A.G. Simpson, "Parametric Modelling of Energy Consumption in Road Vehicles", Ph.D Thesis, The University of Queensland, 2005.

[21] S.S. Reddy, "Optimal operation management of Grid-Connected microgrids under uncertainty", Indonesian Journal of Electrical Engineering and Computer Science, vol. 16, no. 3, pp. 1163-1170, Dec. 2019.

[22] H. He, R. Xiong, H. Guo, "Online estimation of model parameters and state-of-charge of $\mathrm{LiFePO}_{4}$ batteries in electric vehicles," Applied Energy, vol. 89, no. 1, pp. 413-420, Jan. 2012.

[23] V. Marano, S. Onori, Y. Guezennec, G. Rizzoni, N. Madella, "Lithium-ion batteries life estimation for plug-in hybrid electric vehicles," IEEE Vehicle Power and Propulsion Conference, Dearborn, MI, 2009, pp. 536-543.

[24] Z. Chen, N. Guo, X. Li, J. Shen, R. Xiao, S. Li, "Battery Pack Grouping and Capacity Improvement for Electric Vehicles Based on a Genetic Algorithm,” Energies, vol. 10, pp. 1-15, 2017. 
[25] S.S. Reddy, "Solving optimal generation scheduling problem of Microgrid using teaching learning based optimization algorithm", Indonesian Journal of Electrical Engineering and Computer Science, vol. 17, no. 3, pp. 1632-1638, Mar. 2020.

[26] X. Hu, S. J. Moura, N. Murgovski, B. Egardt, D. Cao, "Integrated Optimization of Battery Sizing, Charging, and Power Management in Plug-In Hybrid Electric Vehicles," IEEE Transactions on Control Systems Technology, vol. 24, no. 3, pp. 1036-1043, May 2016.

[27] S.S. Reddy, "Multi-Objective Based Optimal Scheduling of Microgrid Considering Uncertainties", IEEE International Conference on Cutting-edge Technologies in Engineering (ICon-CuTE), Nov. 14-16, 2019, Lucknow, Uttar Pradesh, India.

[28] B. Bendjedia, N. Rizoug, M. Boukhnifer, F. Bouchafaa, "Hybrid Fuel Cell/Battery Source Sizing and Energy Management for Automotive Applications", IFAC-PapersOnLine, vol. 50, no. 1, pp. 4745-4750, Jul. 2017.

[29] S.S. Reddy, J.Y. Park, C.M. Jung, "Optimal Operation of Microgrid Using Hybrid Differential Evolution and Harmony Search Algorithm", Frontiers in Energy, vol. 10, no. 3, pp. 355-362, Sept. 2016.

[30] L. Zhang, X. Hu, Z. Wang, F. Sun, J. Deng, D.G. Dorrell, "Multiobjective Optimal Sizing of Hybrid Energy Storage System for Electric Vehicles," IEEE Transactions on Vehicular Technology, vol. 67, no. 2, pp. 10271035, Feb. 2018.

[31] S.S. Reddy, "Optimal Operation of Microgrid considering Renewable Energy Sources, Electric Vehicles and Demand Response”, E3S Web of Conferences, vol. 87, pp. 1-6, Mar. 2019.

[32] E. Tara, S. Shahidinejad, S. Filizadeh, E. Bibeau, "Battery Storage Sizing in a Retrofitted Plug-in Hybrid Electric Vehicle," IEEE Transactions on Vehicular Technology, vol. 59, no. 6, pp. 2786-2794, July 2010.

[33] J. Snoussi, S.B. Elghali, M. Benbouzid, M.F. Mimouni, "Optimal Sizing of Energy Storage Systems Using Frequency-Separation-Based Energy Management for Fuel Cell Hybrid Electric Vehicles," IEEE Transactions on Vehicular Technology, vol. 67, no. 10, pp. 9337-9346, Oct. 2018. 